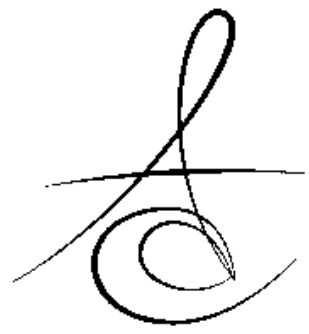

\title{
ODONTOJENİK KİST: ATATÜRK ÜNİVERSİTESİ AĞIZ, DİŞ VE ÇENE CERRAHİSİ ANABİLİM DALI'NA ODONTOJENİK KİST NEDENİYLE BAŞVURAN 100 OLGUNUN KLİNİK VE RADYOLOJİK OLARAK İNCELENMESİ
}

\author{
ODONTOGENIC CYST: CLINICAL AND RADIOLOGICAL EXAMINATION OF \\ ODONTOGENIC CYSTS OF 100 PATIENTS WHO REFERRED TO THE ATATURK \\ UNIVERSITY ORAL AND MAXILLOFACIAL SURGERY DEPARTMENT
}

\author{
Dr. Öğr. Üyesi Gelengül URVASIZOĞLU*
}

Arş. Gör. Berkay AŞKIN*

Makale Kodu/Article code: 3693

Makale Gönderilme tarihi: 24.05.2018

Kabul Tarihi; $\quad 06.11 .2018$

\section{öz}

$\mathrm{Bu}$ çalışmanın amacl, bölgemizde odontojenik kist görülen hastaların demografik bilgilerini ve lezyon lokalizasyonlarını tespit etmek ve bu verileri dünya geneli ile karşılaştırmaktır. Odontojenik kistler oral patolojik lezyonların önemli bir bölümünü oluşturmasına rağmen, çeşitli popülasyonlardaki dağılım modelleri henüz açıklığa kavuşturulamamıştır. Bu çalışma, Atatürk Üniversitesi Diş Hekimliği Fakültesi Ağız, Diş ve Çene Cerrahisi Anabilim Dalı'na 2017-2018 yılları arasında başvuran hastalardan odontojenik kist tanısı alan 100 olgu seçilerek gerçekleştirildi ve tanıyı doğrulamak için histopatolojik inceleme yapıldı. Hastaların demografik bilgileri (yaş ve cinsiyet) ve lezyonun yeri tanımlayıcı istatistikler kullanılarak kaydedildi ve analiz edildi.

Çalışma popülasyonunda erkek-kadın oranı 1.66: 1 olarak bulundu. Hastaların ortalama yaşının 31,2 yıl (yaş aralığı 3-75) olduğu görüldü. Kistlerin \% 48'i maksillada, \% 52'si ise mandibulada bulundu. Radiküler kist(\%56) en sık görülen tipti ve bunu takiben dentigeröz kist(\%16), rezidüel kist(\%15), paradental kist(\%5), odontojenik keratokist(\%5) diğer sık görülen kistler arasındaydı. Ayrıca lateral periodontal kist(\%1) ve erüpsiyon kisti(\%2) de az sayıda vakada gözlendi. Erzurum'daki odontojenik kistlerin dağılım modeli, dünyanın diğer bölgeleriyle benzerdir. Lezyonların kesin tanısı için rutin takibin ve histopatolojik bulguların önemi vurgulandı.

Anahtar Kelimeler: Odontojenik Kist, Histopatoloji, Demografik Faktör

\section{ABSTRACT}

The aim of this study is to determine the demographic information and lesion localization of patients with odontogenic cysts in our region and to compare these data with the rest of the world.

Although the odontogenic cysts constitute a major part of oral pathological lesions, information about their distribution patterns in different populations has been unclear. This study was carried out by collecting 100 patients with a diagnosis of odontogenic cyst from patients admitted to the Department of Oral and Maxillofacial Surgery, Faculty of Dentistry, Ataturk University between 2017-2018 and these were histopathologically re-evaluated to confirm the diagnosis. Demographic information of patients (age and sex) and location of the lesion were recorded and analyzed using descriptive statistics. The male to female ratio was $1.66: 1$ in study population. The mean age of the patients was 31.2 years (range 3-75 years). $48 \%$ of cysts were found in maxilla and $52 \%$ in mandible. Radicular cyst(\%56) was the most common type, followed by dentigerous cyst(\%16), residual cyst(\%15), paradental cyst(\%5), and odontogenic keratocyst(\%5). Lateral periodontal cyst(\%1) and eruption cyst (\%2) were also observed in limited number of cases.

The distribution pattern of odontogenic cysts in Erzurum is relatively similar to that in other parts of the world. The importance of routine follow-up examinations and histopathological finding are reported for final diagnosis.

Key Words: Odontogenic Cyst, Histopathology, Demographic Factor

* Atatürk Üniversitesi Diş Hekimliği Fakültesi Ağız, Diş ve Çene Cerrahisi AD, Erzurum. 


\section{GİRİş}

WHO sınıflamasına(2017) göre odontojenik kistler inflamatuar ve gelişimsel olmak üzere 2 gruba ayrıır $^{1}$. İnflamatuar kistler inflamasyon sonucu gelişir, ancak gelişimsel kist oluşumunu başlatan faktörler tam olarak bilinmemektedir. Gelişimsel kistler, ağız mukozası epitelinden ve çene proliferasyonunu sağlayan epitelden (Malassez epitelyum artıklarından) gelişebilir${ } \mathrm{er}^{2}$. İnflamatuar odontojenik kistler radiküler, paradental, rezidüel olmak üzere kendi içinde 3 gruba ayrılır. Gelişimsel odontojenik kistler; dentigeröz kist, odontojenik keratokist, erüpsiyon kisti, lateral periodontal kist, bortryoid odontojenik kist, glandüler odontojenik kist, kalsifiye odontojenik kist, ortokeratinize odontojenik kist olmak üzere 8 gruba ayrılır ${ }^{1}$.

Odontojenik kistler, tanısal olarak klinisyenleri zorlayabilen lezyonlar olarak görülebilir ancak bunların çoğu kolayca sınıflandırıı. Odontojenik kistler radyografilerde sınırları iyi tanımlanmış lezyonlar olarak görülebilse de dentigeröz kist, keratokist, kısmen de ameloblastomadaki kistik değişimler aynı radyografik bulgulara sahip olabilir. Bu çene lezyonlarının ayırıcı tanısı klinik ve radyografik bulguların yanında bazen sadece histolojik bulgularla birlikte netleşir ${ }^{3}$. Ayrıca bu kistlerin, kist duvarlarından kaynaklı karsinomaların gelişme intimalinden dolayı bu lezyonlardan biyopsi yapılması gereklidir ${ }^{4}$.

2017'deki sınıflandırmada yapılan en önemli değişikliklerden ikisi, kalsifiye kistik odontojenik tümör ve keratokistik odontojenik tümörün neoplastik kategoriden (2005) kist kategorisine (2017) taşınmış olmasıdır. Kalsifiye kistik odontojenik tümör artık "kalsifiye odontojenik kist" olarak sınıflandırılmıştır ve keratokistik odontojenik tümör, 2017'de gelişimsel odontojenik kistlerin sınıflandırılmasında odontojenik keratosist (OKC) olarak isimlendirilmiştir ${ }^{1}$.

$\mathrm{Bu}$ lezyonların nüks, agresiflik, genişleyerek büyüme eğilimi ve malignite potansiyeli ile ilgili olarak klinik bulgu ve semptomları ile biyolojik davranışları tiplere göre farklılık göstermektedir. Odontojenik keratosist (OKC) gibi bazı lezyonlar yüksek nüks ${ }^{5-8}$ oranına sahip olup agresif büyüme ${ }^{9}$ özellikleri gösterirken diğer odontojenik kistler tamamen bening özellikler gösterir ayrıca klinik olarak da mükemmel sonuç ve bulgular ile iyileşirler.

Hastalıkların temel yönlerinden biri, demografik ve dağılım paternleridir. Odontojenik kistlere ilişkin bu tür bilgiler, diş hekimleri veya uzmanlarından (çoğunlukla cerrah ve radyolog), diş hekimliği fakültelerinden ve oral patoloji birimleri gibi çeşitli kaynaklardan elde edilebilir.

Oral Patoloji servislerindeki dosyalar odontojenik lezyonlar hakkında en geçerli erişilebilir bilgi kaynaklarından biri olarak kabul edilmektedir ve bu konudaki hemen hemen tüm çalışmalar bu kaynaklara dayanmaktadır ${ }^{10-12}$. Ancak lezyonların kesin teşhis ve tanısı için lezyonların klinik ve radyolojik incelemelerle bir bütün olarak değerlendirilmesi gereklidir.

\section{MATERYAL VE METOD}

$\mathrm{Bu}$ çalışma Atatürk Üniversitesi Diş Hekimliği Fakültesi araştırma etik kurulu tarafından 47 sayılı 5/ 2018 oturum kararıyla onaylandı. Hasta popülasyonu, Atatürk Üniversitesi Diş Hekimliği Fakültesi Ağız, Diş ve Çene Cerrahisi A.D. 'ye 2017-2018 tarihleri arasında başvuran hastalar arasından çalışmaya uygun olan toplam 100 hastayı içerecek şekilde seçilmiştir. ÇaIışma panoramik radyografide geniş radyolüsent lezyona sahip hastaları içermektedir. Semptomatik ve enfekte olan lezyona sahip hastaların yanı sıra histolojik değerlendirilme ile sonucu doğrulanamayan ve histolojik sonucuna ulaşılamamış hastalar çalışma dışında bırakılmıştır.

Histolojik değerlendirme 2017 yılında yapılan WHO sınıflamasına göre Atatürk Üniversitesi Tıbbi Patoloji A.D. 'nda değerlendirildi. Son tanı tek başına histopatolojik değerlendirme ile yapılamadıysa, klinik ve radyografik bulgular ışığı altında tekrar değerlendirildi.

Çalışmaya dahil edilen vakalarda hastaların demografik bilgileri (yaş ve cinsiyet) ve lezyonun yeri kaydedildi. Her çenedeki tutulum alanı dört ana grup altında aşağıdaki şekilde sınıflandırılmıştır: anterior, premolar, 1. ve 2. molar ve 3. molar. Yukarıda gösterilen birden fazla alanı içeren durumlar için, "birden fazla konum" (BFK) olarak tanımlanan başka bir alt kategori dikkate alınmıştır. ( Grafik 1.)

\section{SONUÇLAR}

Çalışma kriterlerine uyan ve incelemeye tabi tutulan toplam 100 hasta kaydı histopatolojik olarak değerlendirmeye alınmıştır. Kadınlarda 40 olgu (\%40), erkeklerde 60 olgu (\% 60) olmak üzere toplamda 100 
olgu çalışmaya dâhil edilmiştir. Çalışma popülasyonunda erkek-kadın oranı 1.66/1 olarak bulundu.

Maksillada 48(\% 48) ve mandibulada 52(\% 52) olmak üzere toplamda 100 odontojenik kist tespit edildi. Olguların toplamının üçte birinden daha fazlasında çenelerin ön bölgesinde lezyon vardı.(Grafik 1) Hastaların yaşı ortalama 31,2 olup yaş aralığı ise 3 ila 75 arasında değişmektedir. Hastaların \% 55'si 30 yaşın altındaydı. Farklı tipteki odontojenik kistlerin göreceli sıklığı Tablo 1'de gösterilmiştir.

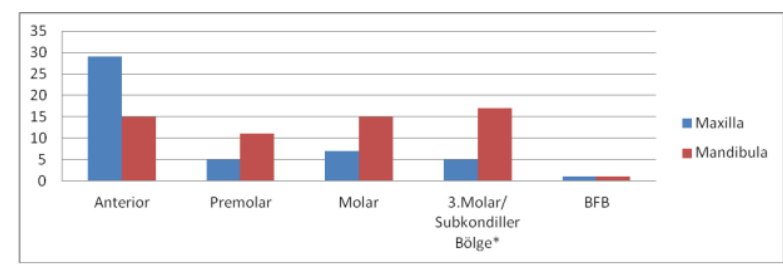

Grafik 1. Odontojenik Kistlerin(OK) görüldüğü bölgelerin dağılımı/BFB: Aynı çende aynı anda birden fazla görüldüğü durumlar

*Subkondiller bölgede sadece bir adet odontojenik kist görülmüştür ve 3 . Molar bölgedeki kistlere dahil edilmiştir.

Tablo 1. Çalışmamızda görülen odontojenik kistlerin sayıları ve çalışmadaki genel ortalama ile karşılaştırıması

\begin{tabular}{|l|c|c|c|}
\hline Kist Tipleri & Sayı & $\begin{array}{c}\text { Gruplarda \% } \\
\text { olarak } \\
\text { görülme } \\
\text { sıklığı }\end{array}$ & $\begin{array}{c}\text { Tüm } \\
\text { kistlerde } \\
\text { \% olarak } \\
\text { görülme } \\
\text { sıklığı }\end{array}$ \\
\hline \multicolumn{3}{|c|}{ Gelişimsel Odontojenik Kistler } \\
\hline Dentigeröz Kist & 16 & 66,6 & 16 \\
\hline Erüpsiyon Kisti & 2 & 8,4 & 2 \\
Odontojenik Keratokist & 5 & 20,8 & 5 \\
\hline Lateral Periodontal Kist & 1 & 4,3 & 1 \\
\hline Glandüler Odontojenik Kist & 0 & 0 & 0 \\
\hline Botryoid Odontojenik Kist & 0 & 0 & 0 \\
Kalsifiye Odontojenik Kist & 0 & 0 & 0 \\
Ortokeratinize Odontojenik Kist & 0 & 0 & 0 \\
\hline \multicolumn{2}{|c|}{ Inflamatuar Odontojenik Kistler } \\
\hline Radiküler Kist & 56 & 72,3 & 56 \\
\hline Paradental Kist & 5 & 6,5 & 5 \\
\hline Rezidüel Kist & 15 & 19,7 & 15 \\
\hline Toplam & 100 & 100 & 100 \\
\hline
\end{tabular}

Çalışmamızda en sık saptanan odontojenik kist tipi olan radiküler kistte erkek-kadın oranı 1.94 olarak görüldü. (Tablo 2) Lezyon ağırlıklı olarak 10 ila 39 yaşları arasında (\% 71) görülmüştür. 28 olguda, maksiller ön dişler en fazla etkilenen bölgeydi. Mandibular molar dişler en çok etkilenen ikinci bölgeydi (Grafik 2).

Tanı konulan ikinci en sık odontojenik kist tipi olan dentigeröz kist 16 (\% 16) olguda görüldü. (Resim
1) Erkek: kadın oranı 1,2: 1 olarak görüldü.(Tablo 2) Hastaların yaş ortalaması 27,2'ydi ve hastaların çoğunluğu (\% 70) 30 yaşın altındaydı. Mandibular 3. molar dişler en çok etkilenen bölgelerdi.(Grafik 3)

Rezidüel kistler, 15 vaka (\% 15) ile üçüncü en yaygın tipti. (Resim 2) Dokuz lezyon (\% 60) erkeklerde, altı lezyon (\% 40) kadınlarda tespit edildi ve erkek kadın oranı 1.66:1 idi.(Tablo 2) Çalışmamızda rezidüel kistin görülme yaş aralığı olarak da 15-70 yaş arası gibi geniş bir yaş aralığı bulunmaktaydı. Mandibular molar bölge ve maksiler anterior bölge en sık etkilenen bölgelerdi.

Beş olguda (\% 5) paradental kist saptandı. Erkeklerde daha sık teşhis edildi ve çoğunlukla yaşamın birinci ve üçüncü on yıllarında (\% 80) saptandı. Mandibular üçüncü molar alan en yaygın etkilenen bölgeydi.

Odontojenik keratokist toplam 5 vakada (\% 5) görüldü. (Resim 3) Bir lezyon (\% 20) erkeklerde, dört lezyon (\% 80) kadınlarda tespit edildi. (Tablo 2) Görülme yaşı yaşamın üçüncü ve dördüncü dekatları olarak tespit edildi. Üç hastada lezyonun görülme yerinin mandibular üçüncü molar bölgede, bir hastada subkondiller bölgede ve bir hastada da mandibula ön bölgede olduğu saptandı. (Resim 4)

Lateral periodontal ve erüpsiyon kisti görülen diğer kist türleriydi. Bu odontojenik kistler baskın olarak mandibula yerleşimliydi.

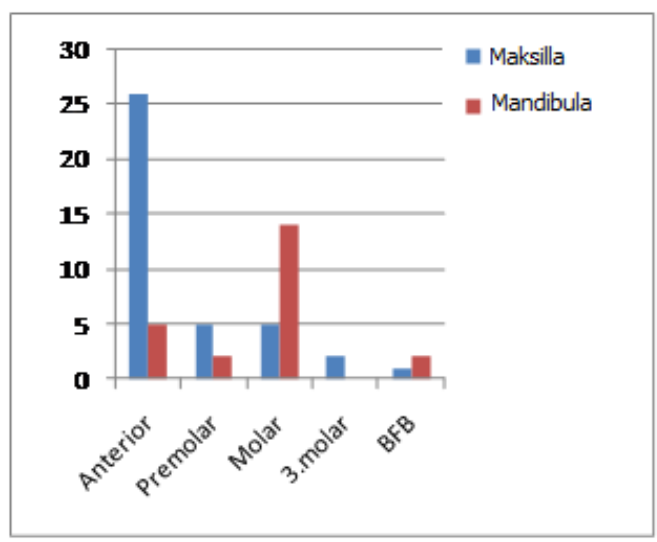

Grafik 2. Radiküler kistin şematik olarak dağılım bölgeleri 


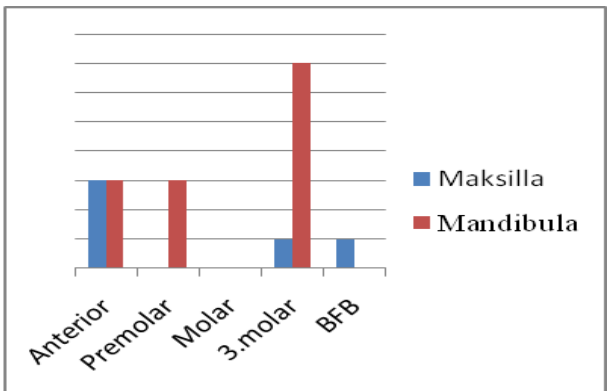

Grafik 3. Dentigeröz kistin şematik olarak dağılım bölgeleri

Tablo 2. Odontojenik kistlerin cinsiyete ve yaşa göre dağıımı(n:100)

\begin{tabular}{|l|cc|cc|cc|c|l|}
\hline Kistin Tipi & \multicolumn{2}{|l|}{$\begin{array}{l}\text { Görülme } \\
\text { Sıklığı } \\
\text { N }\end{array}$} & \multicolumn{2}{|c|}{$\begin{array}{c}\text { Erkek } \\
\text { N }\end{array}$} & $\begin{array}{l}\text { Kadın } \\
\text { N } \\
\%\end{array}$ & $\begin{array}{l}\text { E/K } \\
\text { Oranı }\end{array}$ & $\begin{array}{l}\text { Yaş } \\
\text { Aralığı }\end{array}$ \\
\hline Radiküler & 56 & 56 & 37 & 37 & 19 & 9 & $1,94: 1$ & $13-75$ \\
\hline Rezidüel & 15 & 15 & 9 & 9 & 6 & 6 & $1,66: 1$ & $15-70$ \\
\hline Paradental & 5 & 5 & 3 & 3 & 2 & 2 & $1,66: 1$ & $17-39$ \\
\hline Dentigeröz & 16 & 16 & 9 & 9 & 7 & 7 & $1,2: 1$ & $9-58$ \\
\hline Keratokist & 5 & 5 & 1 & 1 & 4 & 4 & $1: 4$ & $33-58$ \\
\hline $\begin{array}{l}\text { Lateral } \\
\text { Periodontal }\end{array}$ & 1 & 1 & 0 & 0 & 1 & 1 & $1: 0$ & 24 \\
\hline Erüpsiyon & 2 & 2 & 1 & 1 & 1 & 1 & $1: 1$ & $3-5$ \\
\hline Botryoid & 0 & 0 & 0 & 0 & 0 & 0 & 0 & 0 \\
\hline Glandüler & 0 & 0 & 0 & 0 & 0 & 0 & 0 & 0 \\
\hline Kalsifiye O.K & 0 & 0 & 0 & 0 & 0 & 0 & 0 & 0 \\
\hline $\begin{array}{l}\text { Ortokeratinize } \\
\text { O.K. }\end{array}$ & 0 & 0 & 0 & 0 & 0 & 0 & 0 & 0 \\
\hline Toplam & 100 & 60 & & 40 & & \\
\hline
\end{tabular}

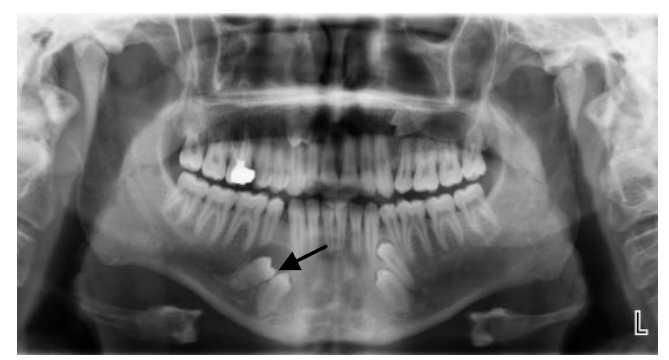

Resim 1. Panoramik röntgende ok ile gösterilen radyolüsent lezyon (dentigeröz kist)

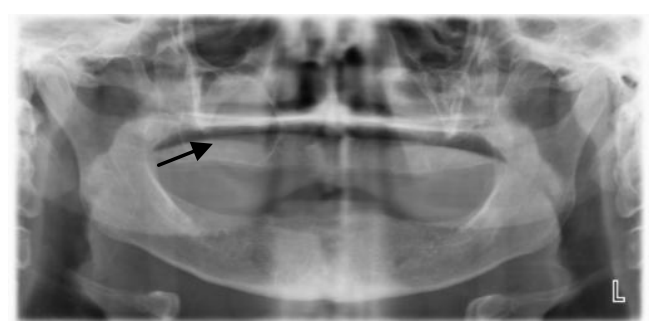

Resim 2. Panoramik röntgende ok ile gösterilen radyolüsent lezyon (rezidüel kist)

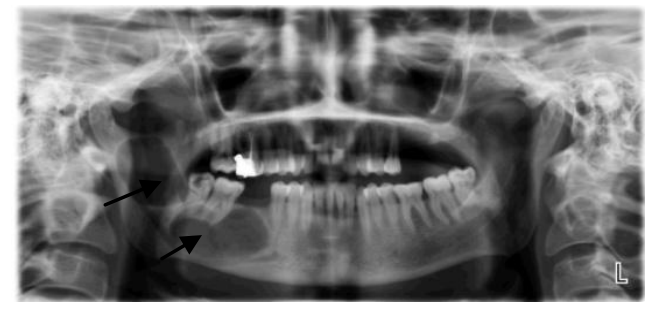

Resim 3. Panoramik röntgende ok ile gösterilen radyolüsent lezyon (odontojenik keratokist)

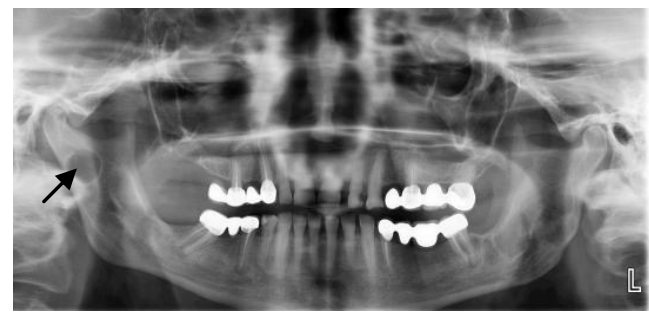

Resim 4. Panoramik röntgende ok ile gösterilen radyolüsent lezyon (odontojenik keratokist)

\section{TARTIŞMA}

Odontojenik kistler, periapikal lezyonları çevreleyen komşu dokulara uzanarak genişleyebilirler. Odontojenik kistlerinin genişlemesi, anatomik bölgelere bağlı olarak gerçekleşmektedir. Mandibulada görülen odontojenik kistler, mandibular kanaldaki sinir ve damar paketine büyüyerek uzanabilir. Kist, üçüncü molar diş çevresinde yer alırsa mandibulanın ramus ve angulus bölgesine doğru genişleyerek büyür.

Literatürdeki bilgilere göre odontojenik kistler genellikle maksillada daha fazla (1.5:1) lokalize olmaktadır. Maksillada daha fazla yerleşmelerinin maksilla ve mandibuladaki kemik yapısının farklıı̆ından kaynaklandığı düşünülmektedir ${ }^{2}$. 2012 yılında Ertem ve ark. tarafından yapılan çalışmada da benzer şekilde maksilladaki görülme sıklığının mandibulaya göre 1.7 kat daha fazla olduğu belirlenmiştir ${ }^{13}$. Bizim çalışmamızda da olguların yirmi sekizinin görüldüğü maksilla anterior bölge, kistlerin görülme yerleri kıyaslandığında da en sık görülme bölgesi olarak tespit edilmiştir.

Kemiğin yapısından dolayı, maksilladaki lezyonun kemik içerisinde genişlemesi daha kolaydır. Lezyonların, sinüsün tamamı hatta burun boşluğunun tabanını işgal ettiği bulunmuştur ${ }^{14,15}$. Maksiller kistler nazal boşluğun şeklini değiştirmeye meyillidir. Maksillada gelişen kistler kök apekslerine komşu maksiller sinüslere doğru gelişirse, kist yavaşça sinüs boşluğuna

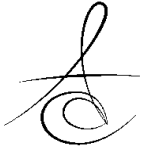


ilerler ve sinüs membranının yer değiştir- mesine yol açabilir. Genişleyen kistler, genel olarak yüzde herhangi bir deformasyona neden olmaz ${ }^{16}$. Literatürdeki bilgilere benzer şekilde çalışmamızda maksillada görülen odontojenik kistler nedeniyle yüzde belirgin bir asimetri saptanmadı.

Kistin büyümesi, dişin apeksinde yer alan sinir ve damar paketinde atrofiye neden olabilir. Bu durum dişin içerisine yetersiz kan akımı ulaşmasına neden olacağından nihayetinde dişte nekroz oluşumu ile sonuçlanabilir ${ }^{17}$. Klinik olarak geniş lezyonlar, kronik lezyonun akut alevlenmesini işaret eden, aralıklarla ortaya çıkan ağrılarla birlikte görülür. Ortaya çıkan bu ağrılar, tanının konmasına yardımcı olur.

Mandibulada görülen büyük boyuttaki lezyonların çoğu, alveolaris inferior sinir dalındaki duyusal bozukluklar ile ilişkilidir ${ }^{18}$. Bizim çalışmamızda mevcut odontojenik kist nedeniyle N. Alveolaris İnferior'da duysal bozukluk yaşayan hasta anamnezi bildirilmedi.

Çalışmamızda en sık görülen lezyonlar radiküler kist(\%56), dentigeröz kist(\%16) ve rezidüel kist(\%15) olarak tespit edildi. Bu sonuç diğer çalışmalarda ortaya çıkan sonuçlarla uyumludur ${ }^{10-12,19-21}$. Ancak, pediatrik hastalarda durum biraz daha farklıdır ${ }^{22}$. Daimi dişlenme süreci 1 . azı dişlerin sürmesiyle başlamaktadır. İnflamatuar kaynaklı odontojenik kistlerin oluşması için ise uzun süreli bir kronik inflamasyon süreci gerekmektedir. Bu yüzden pediatrik hasta gruplarında, normalde en çok görülen radiküler kist ve rezidüel kistlerin görülme ihtimali daha düşüktür.

Odontojenik kistlerin en sık görülenleri olan radiküler kistler, pulpitisi takiben pulpal nekrozun bir sonucu olarak gelişirler ve dolayısıyla inflamatuar bir kökene sahiptirler. Radiküler kistler çalışmamızda lezyonların toplamda \% 56'sını oluşturdular. Benzer çalışmaların çoğu, \% 47 ile \% 58 arasında göreceli bir sıklık bildirmiştir ${ }^{10,12,20}$. Birkaç çalışmada ise görülme sıklığı \% 60'ın üzerinde bulunmuştur ${ }^{4}$ 23, 24 .

Çalışmamızda radiküler kistlerin görülme sıklığını erkeklerde kadınlara göre 1.94 kat daha fazla bulduk. Yapılan diğer çalışmalarda radiküler kistin kadınlarda daha fazla görüldüğü bildirilmiştir ${ }^{4}$. 10 ila 30 yaş arası hastalarda radiküler kistlerin görülme sıklığı yaklaşık \% 60 olarak bulundu. Bu diğer çalışmalarla karşılaştırıldığında radiküler kistlerin çok daha erken

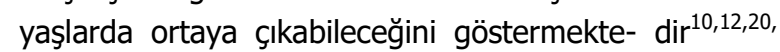
21,23 . Basit çürük önleyici tedbirler, daha kolay ve erişilebilir ağız sağlığı hizmetleri bu inflamatuar lezyonları önlemeye veya ertelemeye yardımcı olabilir. Radiküler kist, daha önce yayınlanmış çalışmalarda olduğu gibi, ağırlıklı olarak maksiller ön bölgede daha sık gözlendi ${ }^{10,12,19,21,23,24}$.

Olguların \% 16'sını oluşturan dentigeröz kist, bu çalışmada en sık görülen ikinci lezyondur. Dentigeröz kistin radyografik görünümü tipik olmakla beraber radyografilerde dişin kronunu çevreleyen iyi sınırlı radyolüsent lezyon şeklinde görülür. Literatürde görülme sıklığı \% 15 ile \% 25 arasında olduğu bildirilmiştir ${ }^{10,12,20,23,24}$. Çalışmamızda dentigeröz kist olgularının, erkeklerde görülme sıklığının kadınlardan fazla olması diğer çalışmalarla uyumluydu ${ }^{12,19-21,24}$. Pik insidansı, Ledesma-Montes ve ark. 'nın ${ }^{19}$, ikinci ve üçüncü on yıllarda pik insidansı bulgularına paraleldi ${ }^{23,24}$.

Odontojenik keratokistlerin, radyografik görüntülerde geniş kistik ve neoplastik lezyonları taklit ettiği bilinmektedir. Çalışmamızdaki olguların \% 5'i odontojenik keratokist kriterlerini karşılamıştır. Bu rakam \% $1,3-\% 11,6^{10,21,23,24}$ arası bir sıklık bildiren diğer çalışmalarla benzerdir. Lezyonun erkek hastalarda, posterior mandibular bölgede, ikinci ve üçüncü dekatlarda daha fazla görüldüğü literatürde belirtilmiştir ${ }^{10,21,23-25}$. Bizim çalışmamızda toplamda beş hastaya odontojenik keratokist tanısı konulmuş olup lezyonların üçü 3 . molar diş bölgesinde görülmüştür. Hasta popülasyonunu ise dört kadın ve bir erkek hasta oluşturmaktadır. Diğer çalışmalarda ${ }^{12,26}$ maksiller anterior bölge odontojenik keratokist için en yaygın ikinci görülme bölgesiydi. Bu bölgede, Ali ve Baughman'ın bildirdiği gibi, odontojenik keratokistlerin radiküler kist veya granülom gibi inflamatuar lezyonlar lehine yanlış tanı konma riski yüksektir ${ }^{26}$. Bu bölgedeki odontojenik keratokist için nüks oranının \% 70 kadar yüksek olduğu bildirilmiştir ${ }^{27}$. Maxillanın anterior bölgesi, periapikal radyolüsensilerin histopatolojik olarak incelenmesinin gerekli olduğu kritik bir bölgedir. Bu bölgedeki periapikal lezyonların radiküler kist lehine değerlendirilip histopatolojik olarak incelenmemesi nükslere yol açabilir. Odontojenik keratokistin nüks oranının çok yüksek olduğu bilinmektedir. Hasta sayısındaki varyasyonlar ve takip muayenelerinin süresiyle ilgili olarak \% 18'den $\%$ 58,3'e kadar nüks oranları bildirilmiştir ${ }^{25,} 27$.

Literatürde Gorlin sendromu ile ilişkili olabilecek çok sayıda odontojenik keratokist vakası bildirilmiştir. Bizim çalışmamızda odontojenik keratokist vakaları diğer hastalıklarla ilişkili olmayan ayrı lezyonlar olarak değerlendirildi. 
Rezidüel kist, radiküler kist ile benzerdir; nedensel diş çıkarıldıktan sonra kalan kiste rezidüel kist denir. Çalışmamızda rezidüel kistin görülme insidansı tüm vakaların \% 15'ini oluşturmuştur. Yapılan diğer çalışmalarla kıyaslandığında bizim çalışmamızda

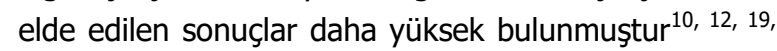
20. Lezyonun cinsiyet, bölge ve yaş dağılımı ile ilgili bulgularımız, ayrıntılı bilgi veren diğer çalışmalarla uyumluydu ${ }^{10,12}$.

İnflamatuar orijinli bir başka odontojenik kist olan paradental kist, daha önce perikoronit meydana gelen kısmi sürmüş mandibular üçüncü azı dişlerle ilişkilidir. Literatürdeki lezyonun göreceli sıklığı \% $1^{\prime} \operatorname{den}^{23,28} \%$ 5,6'ya ${ }^{10}$ kadar değişmiştir. Bizim çalışmamızda beş olgu paradental kist olup mandibuladaydı ve hemen hemen hepsi üçüncü azı dişler ile ilişkiliydi. Paradental kistlerin çoğunluğu yaşamın üçüncü on yılında görülmektedir ${ }^{10,29}$. Mandibular üçüncü molar dişlerde, özellikle de kısmi sürmüş olanlarda erüpsiyon süresi uzadıkça görülme ihtimalleri artmaktadır. Bizim çalışmamızda üç erkek ve iki kadın hasta olmak üzere toplam beş olguda paradental kist görülmüştür.

Bulgularımıza dayanarak, bölgemizde görülen odontojenik kistlerin dağılımı, dünyanın diğer bölgelerinde yapılan çalışmalarla nispeten benzerdir. Lezyonların kesin tanısı için histopatolojik örnek alımı ve rutin takip muayenelerinin yapılması hem kesin tanının konmasına yardımcı olur hem de gelişebilecek olan nükslerin önüne geçilmesi sağlanmış olur. Çalışmamızda kesin tanının konması için lezyonların klinik, radyolojik ve histopatolojik olarak bir bütün şeklinde değerlendirilmesinin önemi vurgulanmıştır.

Gelengül Urvasızoğlu: ORCID ID: 0000-0003-1628-7571 Berkay Aşkın: ORCID ID: 0000-0001-9104-4946

\section{KAYNAKLAR}

1. Soluk-Tekkeşin M, Wright JM. The World Health Organization Classification of Odontogenic Lesions: A Summary of the Changes of the 2017 (4th) Edition. Turkish J Pathol, 2018; 34.

2. Varinauskas V, Gervickas A, Rožnova O. Analysis of odontogenic cysts of the jaws. Medicina 2006; 42: 201-7.

3. Robinson RA. Diagnosing the most common odontogenic cystic and osseous lesions of the jaws for the practicing pathologist. Modern Pathol 2017; 30: S96.
4. Sharifian MJ, Khalili M. Odontogenic cysts: a retrospective study of 1227 cases in an Iranian population from 1987 to 2007. J Oral Sci 2011; 53: 361-7.

5. Zhao Y-F, Wei J-X, Wang S-P. Treatment of odontogenic keratocysts: a follow-up of 255 Chinese patients. Oral Surg, Oral Med, Oral Pathol Oral Radiol, and Endod, 2002; 94: 151-6.

6. Zecha JA, Mendes RA, Lindeboom VB, van der Waal I. Recurrence rate of keratocystic odontogenic tumor after conservative surgical treatment without adjunctive therapies-A 35-year single institution experience. Oral Oncol 2010; 46: 740-2.

7. Boffano P, Ruga E, Gallesio C. Keratocystic odontogenic tumor (odontogenic keratocyst): preliminary retrospective review of epidemiologic, clinical, and radiologic features of 261 lesions from University of Turin. J Oral and Maxillofac Surg 2010; 68: 2994-9.

8. Blanas N, Freund B, Schwartz M, Furst IM. Systematic review of the treatment and prognosis of the odontogenic keratocyst. Oral Surg, Oral Med, Oral Pathol, Oral Radiol, and Endod 2000; 90: 553-58.

9. Shear M. The aggressive nature of the odontogenic keratocyst: is it a benign cystic neoplasm? Part 1. Clinical and early experimental evidence of aggressive behaviour. Oral Oncol 2002; 38: 21926.

10. Jones A, Craig G, Franklin C. Range and demographics of odontogenic cysts diagnosed in a UK population over a 30-year period. J Oral Pathol \& Med 2006; 35: 500-7.

11. Mosqueda-Taylor A, Irigoyen-Camacho M, DiazFranco M, Torres-Tejero M. Odontogenic cysts. Analysis of 856 cases. Medicina Oral: Organo Oficial de la Sociedad Espanola de Med Oral y de la Academia Iberoamericana de Pathol y Med Bucal 2002; 7: 89-96.

12. Ochsenius G, Escobar E, Godoy L, Peñafiel C. Odontogenic cysts: analysis of 2.944 cases in Chile. Med Oral, Oral Pathol y Cirugía Bucal (Internet) 2007; 12: 85-91.

13. Ertem SY. 38 Vakalık Seride Çenelerdeki Kistlerin Retrospektif Olarak Değerlendirilmesi. Atatürk Üniv Diş Hek Fak Derg 2012; 22: 139-43. 
14. Silvestre A, Soulie D, Rizzoli P, Helie O, Le GF, Cordoliani $Y$. Dental-radicular cysts invading the maxillary sinus. J Radiol 1995; 76: 379-82.

15. Gibson G, Pandolfi P, Luzader J. Case report: a large radicular cyst involving the entire maxillary sinus. General Dent 2002; 50: 80-1.

16. UJ. M. Principles of Oral and Maxillofac Surg 5th. ed. Blackwell Sci 2001; p.170-95.

17. JI. V. Principles of Fac and Dent Surg. 3rd ed.; Vitebsk: 1998: p. 303-18.

18. Öztan M. Endodontic treatment of teeth associated with a large periapical lesion. Int Endod J 2002; 35: 73-8.

19. Ledesma-Montes C ， Hernández-Guerrero JC , Garcés-Ortíz M . Clinico-pathologic study of odontogenic cysts in a Mexican sample population. Archives of Med Res 2000; 31: 373-6.

20. Meningaud J-P, Oprean N, Pitak-Arnnop $P$, Bertrand J-C. Odontogenic cysts: a clinical study of 695 cases. J Oral Sci 2006; 48: 59-62.

21. Tortorici S, Amodio E, Massenti MF, Buzzanca ML, Burruano F, Vitale F. Prevalence and distribution of odontogenic cysts in Sicily: 1986-2005. J Oral Sci 2008; 50: 15-88.

22. Shah SK, Le MC, Carpenter WM. Retrospective review of pediatric oral lesions from a dental school biopsy service. Pediatric Dent 2009; 31: 149.

23. Grossmann SM, Machado VC, Xavier GM, Moura MD, Gomez RS, Aguiar MCF, Mesquita RA. Demographic profile of odontogenic and selected nonodontogenic cysts in a Brazilian population. Oral Surg, Oral Med, Oral Pathol, Oral Radiol Endod 2007; 104: e35-e41.

24. Bataineh AB, Ma'amon AR, Qudah MAA. The prevalence of inflammatory and developmental odontogenic cysts in a Jordanian population: a clinicopathologic study. Quintessence Int 2004; 35.

25. Chirapathomsakul D, Sastravaha $P$, Jansisyanont $P$. A review of odontogenic keratocysts and the behavior of recurrences. Oral Surg, Oral Med, Oral Pathol, Oral Radiol, and Endod, 2006; 101: 5-9.

26. Ali M, Baughman RA. Maxillary odontogenic keratocyst: a common and serious clinical misdiagnosis. J Am Dent Assoc 2003; 134: 877-83.
27. Myoung $H$, Hong S-P, Hong S-D, Lee J-I, Lim C-Y, Choung P-H, Lee J-H, Choi J-Y, Seo B-M, Kim M-J. Odontogenic keratocyst: review of 256 cases for recurrence and clinicopathologic parameters. Oral Surg Oral Med Oral Pathol Oral Radiol Endod 2001; 91: 328-33.

28. Daley TD, Wysocki GP, Pringle GA. Relative incidence of odontogenic tumors and oral and jaw cysts in a Canadian population. Oral Surg Oral Med Oral Pathol 1994; 77: 276-80.

29. De Sousa SOM, Corrêa L, Deboni MC, De Araújo VC. Clinicopathologic features of 54 cases of paradental cyst. Quintessence Int 2001; 32: 73741.

\section{Yazışma Adresi}

Arş. Gör. Berkay AŞKIN

Atatürk Üniversitesi

Diş Hekimliği Fakültesi

Ağız, Diş Ve Çene Cerrahisi AD.

Erzurum

E-mail: berkay.askin@atauni.edu.tr 